\title{
A post-hoc analysis of the comparative efficacy of canagliflozin and glimepiride in the attainment of type 2 diabetes-related quality measures
}

\author{
Charmi A. Patel ${ }^{1 *}$, Robert A. Bailey ${ }^{1}$, Ujjwala Vijapurkar ${ }^{2}$ Gary Meininger $^{2}$ and Lawrence Blonde ${ }^{3}$
}

\begin{abstract}
Background: The randomized, double-blind CANTATA-SU (CANagliflozin Treatment And Trial Analysis Sulfonyl Urea) clinical trial compared the use of canagliflozin (100 mg or $300 \mathrm{mg}$ ) and maximally tolerated glimepiride (6-8 mg) over 104 weeks as add-on therapy for patients with type 2 diabetes mellitus (T2DM) inadequately controlled with metformin. Compared with glimepiride, canagliflozin use was associated with durable reductions in glycated hemoglobin (A1C), blood pressure (BP), and body weight. The aim of this post-hoc analysis of the CANTATA-SU trial was to assess the comparative efficacy of canagliflozin and glimepiride in the attainment of recently updated diabetes-related quality measures (QMs) for up to 104 weeks of treatment.

Methods: This post-hoc analysis evaluated the proportions of patients achieving individual diabetes-related QMs using data from the randomized, double-blind, Phase 3 CANTATA-SU trial. Change in A1C from baseline, and proportions of the study population achieving QMs: A1C $<7.0 \%,<8.0 \%$, and $>9.0 \%$ were assessed. Secondary endpoints included change in BP from baseline, and the proportions of the study population achieving QMs related to $\mathrm{BP}$ and body weight.
\end{abstract}

Results: The proportions of patients in the canagliflozin $100 \mathrm{mg}$, canagliflozin $300 \mathrm{mg}$, and glimepiride groups meeting criteria for all QMs were similar at baseline. At 52 and 104 weeks of treatment, canagliflozin 100 mg and canagliflozin $300 \mathrm{mg}$ provided better or similar reductions in A1C from baseline and achievement of glycemic control QMs compared with glimepiride. At 52 and 104 weeks of treatment, the attainment of QMs related to reductions in body weight and BP all favored canagliflozin compared with glimepiride. Canagliflozin was associated with lower incidence of documented hypoglycemia and severe hypoglycemia compared with glimepiride.

Conclusions: Using the recently adjusted and currently accepted diabetes-related QMs, this analysis observed superior glycemic control with canagliflozin compared with maximally tolerated glimepiride in patients with T2DM who were previously poorly controlled on metformin monotherapy. Compared with maximally tolerated glimepiride, canagliflozin resulted in better achievement of diabetes-related QMs related to weight loss and BP, and was associated with lower incidences of hypoglycemic events.

Trial registration: Clinical trial registry name: CANagliflozin Treatment And Trial Analysis-Sulfonylurea (CANTATA-SU) SGLT2 Add-on to Metformin Versus Glimepiride.

Clinical trial registration number: NCT00968812, registered August 28, 2009.

Keywords: Canagliflozin, Glimepiride, Quality measures, Post-hoc analysis, Phase 3, Glycemic control, Blood pressure, Body weight, A1C

\footnotetext{
* Correspondence: cpatel34@its.jnj.com

${ }^{1}$ Janssen Scientific Affairs, LLC, 1000 Route 202 South, Raritan, NJ 08869, USA

Full list of author information is available at the end of the article
} 


\section{Background}

The attainment of good glycemic control is a major goal in the treatment of type 2 diabetes mellitus (T2DM). Guidelines issued jointly by the American Diabetes Association (ADA) and European Association for the Study of Diabetes (EASD), and those from the American Association of Clinical Endocrinologists and the American College of Endocrinology (AACE/ACE), all emphasize the importance of achieving glycemic goals, as measured by glycated hemoglobin (A1C) but stress the need for the individualization of treatment to meet the needs of each specific patient [1-7]. In addition to the use of clinical guideline-based glycemic goals, there has been an increased focus in recent years on the use of quality measures (QMs) as benchmarks to evaluate patient outcomes, and as reporting tools aimed at improving the health of the overall population and reducing healthcare costs [8]. With estimated diabetes-related healthcare costs amounting to $\$ 322$ billion in the United States (US) in 2012 [9], there is a clear need for the measurement of outcomes associated with improved health while at the same time reducing the financial burden. The National Committee for Quality Assurance has established the HEDIS (Healthcare Effectiveness Data and Information Set) Comprehensive Care measures, which include measures related to T2DM [10]. HEDIS measures allow for evidence-based comparisons of quality performance across different health plans. Other organizations have established their own QMs for diabetes management, including the Health Resources and Services Administration's Health Disparities Collaborative, Better Health's Clinical Advisory Committee, and the Centers for Medicare and Medicaid [11-13].

In April 2015, a number of changes were made to the HEDIS diabetes-related QMs to bring them into line with the recent clinical guidelines [14]. These changes included keeping the A1C to $<7.0 \%$ goal for a selected population without comorbid conditions and looking more closely at patients with $\mathrm{A} 1 \mathrm{C}<8.0 \%$ (considered to be controlled) as well as patients with $\mathrm{A} 1 \mathrm{C}>9.0 \%$ (considered to be poorly controlled); redefining blood pressure (BP) control as $<140 / 90 \mathrm{~mm} \mathrm{Hg}$, rather than $<140 / 80 \mathrm{~mm}$ $\mathrm{Hg}$; and removing low density lipoprotein-cholesterol (LDL-C) screening and the LDL-C target of $<100 \mathrm{mg} / \mathrm{dL}$. Modifying the BP control measure aligns the QMs with the most recent hypertension guidelines issued by the Eighth Joint National Committee [15]. The changes regarding LDL-C align the QMs with the latest American College of Cardiology/American Heart Association (ACC/AHA) Task Force on Practice Guidelines [15].

In combination with lifestyle changes, the current ADA/EASD guidelines for the treatment of T2DM advocate a patient-centered approach and endorse the value of different classes of antihyperglycemic agents (AHAs), in addition to metformin, as a component of dual- and triple-drug regimens [1]. Sulfonylureas have been widely used for many years in the management of T2DM because of their low cost and long-term clinical experience. However, they are associated with an increased risk of hypoglycemia and weight gain, and have a relatively low durability compared with some of the other AHAs [2]. The AACE/ACE algorithm in particular emphasizes the use of agents with a low risk of hypoglycemia and/or weight gain [6,7].

Sodium-glucose co-transporter 2 (SGLT2) inhibitors are a new class of AHAs which reduce blood glucose by targeting the kidney to increase urinary glucose excretion. These agents were recently included in the ADA/EASD Algorithm for antihyperglycemic therapy in T2DM [2, 3] and the 2015 AACE/ACE Comprehensive Diabetes Management Algorithm [6, 7]. In addition to improving glycemic control, SGLT2 inhibitors have been shown to reduce body weight and systolic blood pressure (SBP) [16]. Due to their insulin-independent mechanism of action, SGLT2 inhibitors are also associated with a low risk of hypoglycemic episodes when they are used as monotherapy or in combination with other AHAs not associated with a high risk of hypoglycemia (sulfonylureas and insulins can induce hypoglycemia) [17, 18]. Canagliflozin was the first SGLT2 inhibitor approved for use in the US for the improvement of glycemic control in adult patients with T2DM [19].

To date, very few studies have compared the attainment of QMs between different classes of AHAs, and particularly between the older and newer classes of agents. Results of a previous post-hoc analysis suggested that canagliflozin was associated with comparable or superior attainment of QMs when compared with sitagliptin $(100 \mathrm{mg})$ [20]. Additional studies that assess the achievement of QMs amongst the various AHAs are needed to evaluate the quality of care received by patients with T2DM. The randomized, double-blind CANTATA-SU (CANagliflozin Treatment And Trial Analysis Sulfonyl Urea) clinical trial compared the efficacy, safety and tolerability of canagliflozin (100 mg and $300 \mathrm{mg}$ ) and maximally tolerated glimepiride administered over 104 weeks as add-on therapy for patients with T2DM inadequately controlled with metformin. Compared with glimepiride, both doses of canagliflozin were associated with durable reductions in A1C, body weight and SBP [21, 22]. At 52 weeks, canagliflozin $100 \mathrm{mg}$ was shown to be noninferior to glimepiride, and canagliflozin $300 \mathrm{mg}$ was found to be superior to glimepiride in lowering A1C [21]. These effects were found to be durable and were maintained at 104 weeks [22]. Additionally, over 104 weeks, canagliflozin $100 \mathrm{mg}$ and canagliflozin $300 \mathrm{mg}$ were associated with lower incidences of documented hypoglycemia than glimepiride [22]. The aim of the present analysis was 
to assess the comparative efficacy of canagliflozin $100 \mathrm{mg}$, canagliflozin $300 \mathrm{mg}$, and maximally tolerated glimepiride (6-8 $\mathrm{mg})$ in the attainment of the recently updated diabetes-related QMs over 104 weeks of treatment, using data obtained from the CANTATA-SU trial.

\section{Methods}

\section{Patient population}

This analysis used data from the CANTATA-SU trial, details of which (study, inclusion and exclusion criteria, outcomes) have been previously reported $[21,22]$.

Patients $(N=1,450)$ received canagliflozin $100 \mathrm{mg}$, canagliflozin $300 \mathrm{mg}$, or glimepiride during 104 weeks of treatment. Glimepiride could be titrated multiple times and at any point up to 6 or $8 \mathrm{mg} /$ day based on the maximum approved dose in each country. The total treatment phase consisted of a 52-week core double-blind period followed by a 52 -week extension double-blind period. The study compared the efficacy of 2 doses of canagliflozin (100 $\mathrm{mg}$ and $300 \mathrm{mg}$ ) and glimepiride, with respect to the change from baseline in A1C, SBP, diastolic blood pressure (DBP), body weight, fasting plasma glucose, and fasting lipids, among other parameters [21, 22].

\section{Study measures and statistical analyses Efficacy analyses}

Efficacy data from the CANTATA-SU trial were used to evaluate the proportions of patients achieving individual diabetes-related QMs of glycemic control, BP control, and body mass index (BMI)/body weight at baseline, 52 weeks, and 104 weeks.

The initial endpoints analyzed were change in $\mathrm{A} 1 \mathrm{C}$ from baseline, and patients achieving $\mathrm{A} 1 \mathrm{C}<7.0 \%$ or $<8.0 \%$, or who were poorly controlled $(>9.0 \%)$ at Week 52 . Secondary endpoints in this analysis included: change in BP (SBP and DBP) from baseline, patients achieving $\mathrm{BP}<140 / 90 \mathrm{~mm} \mathrm{Hg}$, change in BMI from baseline, patients achieving BMI $\leq 30 \mathrm{~kg} / \mathrm{m}^{2}$, and patients with $\mathrm{BMI} \geq 25 \mathrm{~kg} / \mathrm{m}^{2}$ at baseline who lost $\geq 10 \mathrm{lb}(4.5 \mathrm{~kg})$.

An analysis of covariance (ANCOVA) model with treatment, stratification factors and country as fixed effects, and baseline values as covariates, was used to evaluate changes or percent changes from baseline at Week 52 and Week 104 in the continuous efficacy variables. Odds ratio (OR) and $95 \%$ confidence intervals (CIs) were calculated for the proportion of patients achieving treatment goals based on a logistic model with treatment, stratification factors, and country as fixed effects, and corresponding baseline values as covariates. The analyses were based on the modified intent-to-treat (mITT) analysis set, which included all randomized patients who took at least one dose of double-blind study medication. The post-baseline last observation carried forward (LOCF) imputation method was applied when values for Week 52 or Week 104 were missing. After Day 1 and during the 104-week double-blind treatment phase, glycemic rescue medication (pioglitazone) was administered to patients on maximum background therapy dose level (maximum allowed dose level of glimepiride) who met pre-specified, stringent glycemic rescue criteria [21]. For patients placed on rescue medication during the study, only the data prior to the initiation of rescue medication were used for the analyses.

\section{Safety analyses}

The incidence (i.e., number and percent of patients with 1 or more events in each category) of adverse events (AEs), serious AEs, AEs leading to discontinuation, cardiovascular AEs, and AEs related to study drug were summarized by treatment group and have been reported previously [21, 22].

The safety analysis included the incidence of hypoglycemia, genital mycotic infections (GMIs), urinary tract infections (UTIs), osmotic diuresis-related AEs, and volume-depletion AEs, as well as proportions of patients receiving antihypertensive agents. All data, regardless of the initiation of rescue medication, were used to perform the safety analyses for overall and specific AEs, while data prior to the initiation of rescue medication were used for hypoglycemia only. Results of the safety analysis are given for the core (baseline through 52 weeks) and for the entire treatment period (baseline through 104 weeks).

\section{Results}

Patients

Of the 1,452 patients randomized to study treatment, 1,450 were included in the modified intent-to-treat (mITT analysis set), with 483 patients in the canagliflozin $100 \mathrm{mg}, 485$ patients in the canagliflozin $300 \mathrm{mg}$, and 482 patients in the glimepiride groups. The mean (standard deviation, SD) maximum dose achieved with glimepiride was $5.6(2.3) \mathrm{mg}$ at Week 52, and 5.8 (2.2) $\mathrm{mg}$ at Week 104.

Overall, $67.6 \%$ of patients completed the entire 104week treatment period. The most common reasons for discontinuation across all treatment groups included AEs (7.5 \% of patients), other (7.0\% of patients), and withdrawal of consent (4.5\% of patients). Efficacy and safety analyses were both performed using the mITT analysis set.

\section{Baseline demographics and disease characteristics}

Baseline demographics for the overall population are shown in Table 1. Patients had similar characteristics across different treatment groups. The mean age of the patient population was 56 years, and $52 \%$ of patients were male. Consistent with the regions of the world in 
Table 1 Baseline demographic and anthropometric characteristics in the overall population

\begin{tabular}{|c|c|c|c|}
\hline & $\begin{array}{l}\text { CANA } 100 \mathrm{mg} \\
(\mathrm{N}=483)\end{array}$ & $\begin{array}{l}\text { CANA } 300 \mathrm{mg} \\
(N=485)\end{array}$ & $\begin{array}{l}\text { GLIM } \\
(N=482)\end{array}$ \\
\hline \multicolumn{4}{|l|}{ Sex, n (\%) } \\
\hline Male & $252(52.2)$ & $241(49.7)$ & $263(54.6)$ \\
\hline Female & $231(47.8)$ & $244(50.3)$ & $219(45.4)$ \\
\hline \multicolumn{4}{|l|}{ Age (years) } \\
\hline \multicolumn{4}{|l|}{ Category, n (\%) } \\
\hline$<65$ & $397(82.2)$ & $411(84.7)$ & $399(82.8)$ \\
\hline$\geq 65$ & $86(17.8)$ & $74(15.3)$ & $83(17.2)$ \\
\hline Mean (SD) & $56.4(9.49)$ & $55.8(9.17)$ & $56.3(9.01)$ \\
\hline \multicolumn{4}{|l|}{ Race, n (\%) } \\
\hline White & $323(66.9)$ & $333(68.7)$ & $322(66.8)$ \\
\hline Black/African American & $20(4.1)$ & $18(3.7)$ & $22(4.6)$ \\
\hline Asian & $99(20.5)$ & $93(19.2)$ & $93(19.3)$ \\
\hline Other & $41(8.4)$ & $41(8.5)$ & $45(9.3)$ \\
\hline \multicolumn{4}{|l|}{ Ethnicity, n (\%) } \\
\hline Hispanic/Latino & 86 (17.8) & $80(16.5)$ & 76 (15.8) \\
\hline Not Hispanic/Latino & 395 (81.8) & $404(83.3)$ & 403 (83.6) \\
\hline Not reported & $1(0.2)$ & $1(0.2)$ & $1(0.2)$ \\
\hline Unknown & $1(0.2)$ & $0(0)$ & $2(0.4)$ \\
\hline \multicolumn{4}{|l|}{ Body weight (kg) } \\
\hline Mean (SD) & $86.9(20.06)$ & $86.6(19.48)$ & 86.5 (19.82) \\
\hline \multicolumn{4}{|l|}{ BMI $\left(\mathrm{kg} / \mathrm{m}^{2}\right), \mathrm{n}(\%)$} \\
\hline$<30$ & $215(44.5)$ & $224(46.2)$ & $234(48.5)$ \\
\hline$\geq 30$ & $268(55.5)$ & $261(53.8)$ & $248(51.5)$ \\
\hline Mean (SD) & $31.0(5.29)$ & $31.2(5.39)$ & 30.9 (5.54) \\
\hline
\end{tabular}

$B M I$ body mass index, CANA canagliflozin, GLIM glimepiride, $S D$ standard deviation

which patients were recruited, $67 \%$ of the patients were white, $20 \%$ were Asian, $17 \%$ of patients were Hispanic or Latino, and $4 \%$ were Black /African American. Of the US residents who participated in the study, $16 \%$ were Black/African American. At baseline, the mean body weight was $86.6 \mathrm{~kg}$ and mean baseline BMI was $31.0 \mathrm{~kg} / \mathrm{m}^{2}$; approximately $54 \%$ of patients were defined as obese (BMI $\geq 30 \mathrm{~kg} / \mathrm{m}^{2}$ ) in accordance to the National Institutes of Health criteria [23]. Baseline diabetes disease characteristics of the overall population were also generally similar across the treatment groups (Table 2). All patients had mild-to-moderate hyperglycemia at baseline and a mean duration of diabetes of 6.6 years.

\section{Efficacy/quality measure attainment Efficacy}

The efficacy parameters assessed were change in A1C, body weight, SBP, and DBP from baseline in patients treated with canagliflozin $100 \mathrm{mg}$, canagliflozin $300 \mathrm{mg}$,
Table 2 Baseline diabetes characteristics in the overall population

\begin{tabular}{|c|c|c|c|}
\hline & $\begin{array}{l}\text { CANA } 100 \mathrm{mg} \\
(\mathrm{N}=483)\end{array}$ & $\begin{array}{l}\text { CANA } 300 \mathrm{mg} \\
(N=485)\end{array}$ & $\begin{array}{l}\text { GLIM } \\
(N=482)\end{array}$ \\
\hline \multicolumn{4}{|l|}{ Baseline A1C, n (\%) } \\
\hline$<7.0 \%$ & $59(12.2)$ & $71(14.6)$ & $65(13.5)$ \\
\hline$<8.0 \%$ (good control) & $294(60.9)$ & $294(60.6)$ & $290(60.2)$ \\
\hline$>9.0 \%$ (poor control) & $31(6.4)$ & $34(7.0)$ & $34(7.1)$ \\
\hline Mean (SD) & $7.8(0.78)$ & $7.8(0.78)$ & $7.8(0.80)$ \\
\hline \multicolumn{4}{|l|}{ Baseline FPG (mmol/L) } \\
\hline Mean (SD) & $9.2(2.07)$ & $9.1(2.01)$ & $9.2(2.11)$ \\
\hline \multicolumn{4}{|l|}{ Duration of diabetes (years) } \\
\hline Mean (SD) & $6.5(5.47)$ & $6.7(5.50)$ & $6.6(5.02)$ \\
\hline \multicolumn{4}{|c|}{ Patients with microvascular complications, n (\%) } \\
\hline N & 93 & 87 & 90 \\
\hline Neuropathy & $75(15.5)$ & $62(12.8)$ & $67(13.9)$ \\
\hline Retinopathy & $26(5.4)$ & $37(7.6)$ & $27(5.6)$ \\
\hline Nephropathy & $18(3.7)$ & $15(3.1)$ & $16(3.3)$ \\
\hline \multicolumn{4}{|c|}{ Patients with number of microvascular complications, n (\%) } \\
\hline 0 & $390(80.7)$ & $398(82.1)$ & $392(81.3)$ \\
\hline 1 & $71(14.7)$ & $65(13.4)$ & $72(14.9)$ \\
\hline 2 & $18(3.7)$ & $17(3.5)$ & $16(3.3)$ \\
\hline 3 & $4(0.8)$ & $5(1.0)$ & $2(0.4)$ \\
\hline \multicolumn{4}{|c|}{ Baseline eGFR (mL/min/1.73 m²) } \\
\hline N & 483 & 485 & 481 \\
\hline \multicolumn{4}{|l|}{ Category, n (\%) } \\
\hline$<60$ & $15(3.1)$ & $13(2.7)$ & $10(2.1)$ \\
\hline $60-<90$ & $232(48.0)$ & $232(47.8)$ & $251(52.1)$ \\
\hline$\geq 90$ & $236(48.9)$ & $240(49.5)$ & $220(45.6)$ \\
\hline Mean (SD) & $89.7(19.28)$ & 91.4 (19.36) & 89.5 (17.48) \\
\hline
\end{tabular}

A1C glycated hemoglobin, AHA antihyperglycemic agent, CANA canagliflozin, eGFR estimated glomerular filtration rate, FPG fasting plasma glucose, GLIM glimepiride, $S D$ standard deviation

or maximally tolerated glimepiride $[21,22]$. At Week 52 , both canagliflozin doses achieved reductions in all four efficacy parameters, and changes were maintained at Week 104. Maximally tolerated glimepiride achieved reductions in A1C at both Week 52 and Week 104, but had no effect on SBP and DBP, and a slight increase in body weight (Table 3 ).

\section{Attainment of QMs}

Diabetes-related QM attainment at baseline, 52 weeks, and 104 weeks according to treatment arm is reported in Table 4. In addition to the proportion of patients achieving each measure, differences between treatment groups and the associated $95 \% \mathrm{CI}$ are represented. At baseline, the proportions of patients attaining QMs were generally similar across treatment groups. 
Table 3 Efficacy parameters at Week 52 and Week 104 in the mITT analysis set $[21,22]$

\begin{tabular}{|c|c|c|c|c|}
\hline & & $\begin{array}{l}\text { CANA } 100 \mathrm{mg} \\
(N=483)\end{array}$ & $\begin{array}{l}\text { CANA } 300 \mathrm{mg} \\
(N=485)\end{array}$ & $\begin{array}{l}\text { GLIM } \\
(N=482)\end{array}$ \\
\hline & & $\begin{array}{l}\text { LS mean } \\
\text { change (SE) }\end{array}$ & $\begin{array}{l}\text { LS mean } \\
\text { change (SE) }\end{array}$ & $\begin{array}{l}\text { LS mean } \\
\text { change (SE) }\end{array}$ \\
\hline$A 1 C, \%$ & 52 weeks & $-0.82(0.04)$ & $-0.93(0.04)$ & $-0.81(0.04)$ \\
\hline & 104 weeks & $-0.65(0.04)$ & $-0.74(0.04)$ & $-0.55(0.04)$ \\
\hline $\mathrm{SBP}, \mathrm{mm} \mathrm{Hg}$ & 52 weeks & $-3.3(0.6)$ & $-4.6(0.6)$ & $0.2(0.6)$ \\
\hline & 104 weeks & $-2.0(0.6)$ & $-3.1(0.6)$ & $1.7(0.6)$ \\
\hline $\mathrm{DBP}, \mathrm{mm} \mathrm{Hg}$ & 52 weeks & $-1.8(0.4)$ & $-2.5(0.4)$ & $-0.1(0.4)$ \\
\hline & 104 weeks & $-1.3(0.4)$ & $-2.2(0.4)$ & $-0.0(0.4)$ \\
\hline BW, kg & 52 weeks & $-3.7(0.2)$ & $-4.0(0.2)$ & $0.7(0.2)$ \\
\hline & 104 weeks & $-3.6(0.2)$ & $-3.6(0.2)$ & $0.8(0.2)$ \\
\hline
\end{tabular}

$A 1 C$ glycated hemoglobin, $B W$ body weight, CANA canagliflozin, DBP diastolic blood pressure, GLIM glimepiride, $L S$ least squares, $\mathrm{m} / T T$ modified intent-to-treat, SBP systolic blood pressure, SE standard error
Canagliflozin $100 \mathrm{mg}$ or $300 \mathrm{mg}$ vs. glimepiride at 52 weeks At 52 weeks, there was an increase in the percentage of patients with good glycemic control (A1C $<7.0 \%,<8.0 \%$ ), and a decrease in the percentage of those with poor glycemic control (A1C >9.0\%) (Table 4).

Similar proportions of patients attained A1C $<7.0 \%$ across the treatment groups, with $53.6 \%$ of canagliflozin $100 \mathrm{mg}, 60.1 \%$ of canagliflozin $300 \mathrm{mg}$, and $55.7 \%$ of glimepiride treated patients (canagliflozin $100 \mathrm{mg}$ vs. glimepiride $\mathrm{OR}=0.85$ [95 \% CI $0.65 ; 1.13$ ]; canagliflozin $300 \mathrm{mg}$ vs. glimepiride $\mathrm{OR}=1.18$ [95 \% CI 0.89; 1.56]). $4.3 \%$ more patients treated with canagliflozin $100 \mathrm{mg}$ achieved $\mathrm{A} 1 \mathrm{C}<8.0 \%$; however, the $\mathrm{CI}$ for the difference with glimepiride included 0 (95\% CI $-0.2 ; 8.9)$, with a corresponding OR of 1.42 [95 \% CI 0.94; 2.14]. $4.9 \%$ more patients treated with canagliflozin $300 \mathrm{mg}$ (95\% CI 0.4 ; 9.4) attained this QM compared with glimepiride, with a corresponding OR of 1.57 (95\% CI 1.04; 2.37). No major differences were observed in the proportion of patients with $\mathrm{A} 1 \mathrm{C}>9 \%$ between canagliflozin $100 \mathrm{mg}$, canagliflozin $300 \mathrm{mg}$ and glimepiride (the $95 \%$ CIs for

Table 4 QMs Attainment at Baseline, Week 52 and Week 104 in the overall population

\begin{tabular}{|c|c|c|c|c|c|c|}
\hline \multirow{2}{*}{ Measure } & & \multicolumn{2}{|c|}{ CANA $100 \mathrm{mg}(N=483)$} & \multicolumn{2}{|c|}{ CANA 300 mg $(N=485)$} & \multirow{2}{*}{$\begin{array}{l}\text { GLIM }(N=482) \\
\%\end{array}$} \\
\hline & & $\%$ & $\begin{array}{l}\text { Difference vs. } \\
\text { GLIM, \% (95 \% Cl) }\end{array}$ & $\%$ & $\begin{array}{l}\text { Difference vs. } \\
\text { GLIM, \% ( } 95 \% \text { Cl) }\end{array}$ & \\
\hline \multicolumn{7}{|l|}{$A 1 C$} \\
\hline \multirow[t]{3}{*}{$<7.0 \%$} & Baseline & 12.2 & & 14.6 & & 13.5 \\
\hline & 52 weeks & 53.6 & $-2.3(-8.8 ; 4.3)$ & 60.1 & $4.3(-2.2 ; 10.8)$ & 55.7 \\
\hline & 104 weeks & 42.5 & $-1.4(-7.9 ; 5.1)$ & 50.2 & $6.3(-0.2 ; 12.9)$ & 43.9 \\
\hline \multirow[t]{3}{*}{$<8.0 \%$ (good control) } & Baseline & 61.1 & & 59.9 & & 60.1 \\
\hline & 52 weeks & 88.7 & $4.3(-0.2 ; 8.9)$ & 89.2 & $4.9(0.4 ; 9.4)$ & 84.4 \\
\hline & 104 weeks & 83.9 & $7.9(2.7 ; 13.2)$ & 84.6 & $8.6(3.4 ; 13.9)$ & 75.9 \\
\hline \multirow[t]{3}{*}{$>9.0 \%$ (poor control) } & Baseline & 6.5 & & 7.2 & & 7.2 \\
\hline & 52 weeks & 1.9 & $-2.1(-4.5 ; 0.2)$ & 1.7 & $-2.3(-4.7 ;-0.0)$ & 4.0 \\
\hline & 104 weeks & 2.5 & $-2.8(-5.4 ;-0.1)$ & 1.9 & $-3.4(-5.9 ;-0.8)$ & 5.3 \\
\hline \multicolumn{7}{|l|}{ Blood pressure } \\
\hline \multirow[t]{3}{*}{$<140 / 90 \mathrm{~mm} \mathrm{Hg}$} & Baseline & 74.1 & & 74.2 & & 75.0 \\
\hline & 52 weeks & 83.7 & $10.6(5.2 ; 16.0)$ & 85.4 & $12.3(7.0 ; 17.6)$ & 73.1 \\
\hline & 104 weeks & 79.6 & $5.4(-0.1 ; 10.9)$ & 84.2 & $10.0(4.7 ; 15.3)$ & 74.2 \\
\hline \multicolumn{7}{|l|}{ Body mass index and body weight } \\
\hline \multirow[t]{3}{*}{$\leq 30 \mathrm{~kg} / \mathrm{m}^{2}$} & Baseline & 44.5 & & 46.3 & & 48.1 \\
\hline & 52 weeks & 57.4 & $10.5(4.0 ; 17.1)$ & 55.6 & $8.8(2.2 ; 15.3)$ & 46.9 \\
\hline & 104 weeks & 57.3 & $10.2(3.7 ; 16.7)$ & 54.8 & $7.7(1.2 ; 14.2)$ & 47.1 \\
\hline \multirow[t]{3}{*}{$\geq 25 \mathrm{~kg} / \mathrm{m}^{2}$ but $\geq 10 \mathrm{lb}(4.5 \mathrm{~kg}$ ) weight loss from baseline } & Baseline & & & & & \\
\hline & 52 weeks & 27.1 & $20.2(15.4 ; 25.0)$ & 34.6 & $27.7(22.6 ; 32.7)$ & 6.9 \\
\hline & 104 weeks & 27.9 & $20.0(15.1 ; 24.9)$ & 34.6 & $26.6(21.5 ; 31.7)$ & 7.9 \\
\hline
\end{tabular}




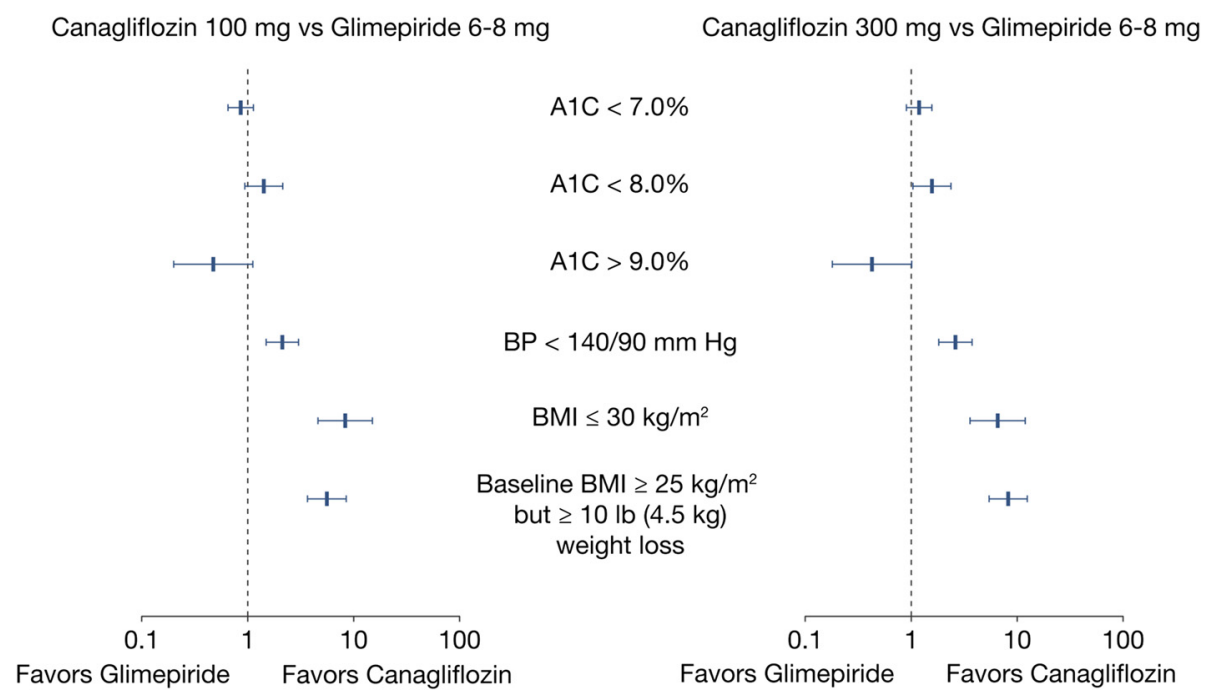

Fig. 1 Odds ratio ( $95 \%$ Cls) of canagliflozin 100 mg vs. glimepiride and canagliflozin $300 \mathrm{mg}$ vs. glimepiride in the proportion of patients achieving QMs at Week 52. Mean (SD) maximum dose of GLIM was 5.6 (2.3) mg. CANA, canagliflozin; GLIM, glimepiride; QMs, quality measures; SD, standard deviation; $95 \% \mathrm{Cl}, 95 \%$ confidence interval

between-group differences included 0 and the $95 \% \mathrm{CIs}$ for ORs included 1) (Table 4 and Fig. 1).

Attainment of the measures related to BP and BMI/ body weight reduction favored both canagliflozin doses compared with glimepiride at 52 weeks (Table 4 and Fig. 1). $10.6 \%$ more patients with canagliflozin $100 \mathrm{mg}$ (95\% CI $5.2 \% ; 16.0 \%$ ) and $12.3 \%$ more patients with canagliflozin $300 \mathrm{mg}$ (95\% CI $7.0 \%$; $17.6 \%$ ) attained BP $<140 / 90 \mathrm{~mm} \mathrm{Hg}$ vs. glimepiride; (Fig. 1). Similarly, $10.5 \%$ more patients with canagliflozin $100 \mathrm{mg}$ (95\% CI $4.0 \%$; $17.1 \%$ ), and $8.8 \%$ more patients with canagliflozin $300 \mathrm{mg}$ (95\% CI $2.2 \%$; $15.3 \%$ ) achieved BMI $\leq 30 \mathrm{~kg} / \mathrm{m}^{2}$ compared with glimepiride. Composite measure of $\geq 25 \mathrm{~kg} / \mathrm{m}^{2}$ and $\geq 10 \mathrm{lb}(4.5 \mathrm{~kg}$ ) weight loss from baseline also favored canagliflozin treatment groups (Table 4 and Fig. 1). There was a $20.2 \%$ (95\% CI $15.4 \%$; $25.0 \%$ ) and $27.7 \%$ (95 \% CI $22.6 \%$; $32.7 \%$ ) increase in the proportion of patients achieving this composite QM in the canagliflozin $100 \mathrm{mg}$ and canagliflozin $300 \mathrm{mg}$ groups, respectively, compared with glimepiride. The $95 \% \mathrm{CIs}$ for the ORs reflecting ontreatment differences after 52 weeks excluded 1 for each BP and BMI/body weight-related quality measure.

\section{Canagliflozin $100 \mathrm{mg}$ or $300 \mathrm{mg}$ vs. glimepiride at 104 weeks} At 104 weeks, in all three treatment groups, the proportion of patients attaining glycemic measures of A1C $<7.0 \%$ and $<8.0 \%$ increased from baseline, while the proportion of patients with poor glycemic control (A1C >9.0\%) decreased from baseline.

Both doses of canagliflozin demonstrated similar attainment of A1C $<7.0 \%$ compared with glimepiride, with
$42.5 \%$ of canagliflozin $100 \mathrm{mg}, 50.2 \%$ of canagliflozin $300 \mathrm{mg}$, and $43.9 \%$ of glimepiride-treated patients (canagliflozin $100 \mathrm{mg}$ vs. glimepiride $\mathrm{OR}=0.89$ [95 \% CI 0.68; 1.18]; canagliflozin $300 \mathrm{mg}$ vs. glimepiride $\mathrm{OR}=1.29$ [95 \% CI 0.98; 1.70]) (Table 4 and Fig. 2). $7.9 \%$ more patients with canagliflozin $100 \mathrm{mg}(95 \%$ CI $2.7 \%$; $13.2 \%)$ attained $\mathrm{A} 1 \mathrm{C}<8.0 \%$ at Week 104 than glimepiride, with a corresponding OR of 1.64 (95 \% CI 1.16; 2.33); while $8.6 \%$ more patients treated with canagliflozin $300 \mathrm{mg}$ (95\% CI 3.4 \%; $13.9 \%$ ) achieved the same QM with an OR of 1.82 (95\% CI 1.27; 2.59). The proportion of patients with A1C $>9.0 \%$ was $3.4 \%$ lower for canagliflozin $300 \mathrm{mg}$ (95\% CI $-5.9 \% ;-0.8 \%$ ) than for glimepiride with a corresponding OR of 0.35 (95\% CI $0.15 ; 0.78)$, but similar when comparing canagliflozin $100 \mathrm{mg}$ with glimepiride $(\mathrm{OR}=0.48$ [95 \% CI 0.23; 1.02]).

Attainment of QMs related to BP favored canagliflozin (Table 4 and Fig. 2); a higher percentage of patients had a BP $<140 / 90 \mathrm{~mm} \mathrm{Hg}$ in the canagliflozin $100 \mathrm{mg}$ (5.4\%, $95 \% \mathrm{CI}-0.1 \% ; 10.9 \%)$ and canagliflozin $300 \mathrm{mg}$ (10.0\%, 95 \% CI $4.7 \%$; $15.3 \%)$ groups compared with glimepiride with ORs of 1.41 (95\% CI 1.01; 1.96) and 2.12 (95 \% CI 1.49; 3.00), respectively.

Similarly, attainment of both BMI/body weight reduction measures favored canagliflozin compared with glimepiride at 104 weeks (Table 4 and Fig. 2). $10.2 \%$ more patients who received canagliflozin $100 \mathrm{mg}$ had a BMI $\leq 30 \mathrm{~kg} / \mathrm{m}^{2}$ at 104 weeks compared with glimepiride, with a corresponding OR of 6.32 (95\% CI 3.64; 10.98), while $7.7 \%$ more patients who received canagliflozin $300 \mathrm{mg}$ (95\% CI $1.2 \%$; $14.2 \%$ ) attained this QM compared with glimepiride $(\mathrm{OR}=4.70$ [95 \% CI 2.68; 8.24]). 


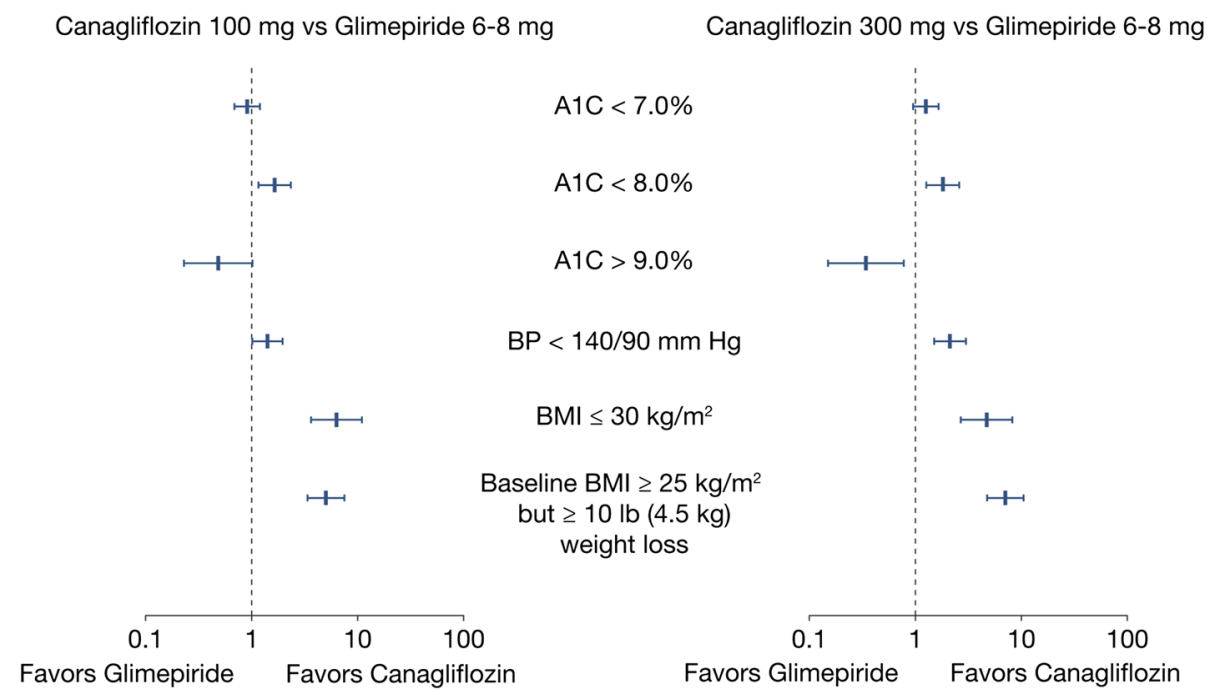

Fig. 2 Odds ratio (95\% Cls) of canagliflozin $100 \mathrm{mg}$ vs. glimepiride and canagliflozin $300 \mathrm{mg}$ vs. glimepiride in the proportion of patients achieving QMs at Week 104. Mean (SD) maximum dose of GLIM was 5.8 (2.2) mg. CANA, canagliflozin; GLIM, glimepiride; QMs, quality measures; $\mathrm{SD}$, standard deviation; $95 \% \mathrm{Cl}, 95 \%$ confidence interval

The composite measure of $\geq 25 \mathrm{~kg} / \mathrm{m}^{2}$ and $\geq 10 \mathrm{lb}(4.5 \mathrm{~kg})$ weight loss from baseline also favored canagliflozin treatment at 104 weeks, with $20.0 \%$ (95\% CI $15.1 \%$; $24.9 \%$, $\mathrm{OR}=5.01 \quad[95 \% \mathrm{CI} 3.36 ; 7.49])$ and $26.6 \%(95 \% \mathrm{CI}$ $21.5 \%$; $31.7 \%$, OR $=7.06$ [95 \% CI 4.75; 10.49]) more patients in the canagliflozin $100 \mathrm{mg}$ and $300 \mathrm{mg}$ groups respectively, compared with glimepiride.

\section{Safety analysis}

A summary of selected AEs for the core and entire treatment periods is presented in Table 5 . As previously reported [20,21], the total number of AEs was similar between groups, while serious AEs tended to occur more frequently with glimepiride. The number of major adverse cardiovascular events and events of hospitalized unstable angina (MACE-plus) were low across all treatment groups, with no increase in MACE-plus associated risk with canagliflozin use.

The total number of documented hypoglycemia episodes, the number of patients with any documented hypoglycemia, and the number of patients with biochemically documented hypoglycemia, or severe hypoglycemia, were lower with canagliflozin $100 \mathrm{mg}$ and $300 \mathrm{mg}$ than with glimepiride. A lower incidence of documented hypoglycemia during both the core and entire treatment periods was observed with canagliflozin compared with glimepiride (baseline through 52 weeks: $5.6 \%, 4.9 \%$, and $34.2 \%$ with canagliflozin $100 \mathrm{mg}, 300 \mathrm{mg}$ and glimepiride, respectively; baseline through 104 weeks: $6.8 \%, 8.2 \%$, and $40.9 \%$ with canagliflozin $100 \mathrm{mg}, 300 \mathrm{mg}$, and glimepiride, respectively). The total numbers of episodes of documented hypoglycemia with canagliflozin $100 \mathrm{mg}$, $300 \mathrm{mg}$, and glimepiride were 67, 33, and 710 during the core period, and 106,100, and 1,189 during the entire treatment period, respectively.

During both the core and entire treatment periods, the incidence of GMIs in both male and female patients was higher in those treated with canagliflozin $100 \mathrm{mg}$ and $300 \mathrm{mg}$ compared with glimepiride (baseline through 52 weeks in males: $6.7 \%, 8.3 \%$, and $1.1 \%$; in females: $11.3 \%, 13.9 \%$, and $2.3 \%$, respectively; baseline through 104 weeks in males: $9.5 \%, 9.1 \%$, and $1.9 \%$; in females: $13.9 \%, 15.6 \%$, and $2.7 \%$, respectively). Similarly, patients treated with canagliflozin $100 \mathrm{mg}$ and $300 \mathrm{mg}$ had a higher incidence of UTIs compared with glimepiride (baseline through 52 weeks: $6.4 \%, 6.4 \%$, and $4.6 \%$; baseline through 104 weeks: $10.6 \%, 8.7 \%$, and $6.8 \%$, with canagliflozin $100 \mathrm{mg}, 300 \mathrm{mg}$ and glimepiride, respectively), as well as a higher incidence of osmoticdiuresis-related AEs (baseline through 52 weeks: $5.6 \%$, $6.2 \%$, and $1.7 \%$; baseline through 104 weeks: $5.8 \%$, $6.6 \%$, and $2.1 \%$, respectively). The incidence of volume depletion AEs was low and comparable across treatment groups (baseline through 52 weeks: $1.7 \%, 1.9 \%$, and $1.7 \%$; baseline through 104 weeks: $1.7 \%, 2.5 \%$, and $2.3 \%$ with canagliflozin $100 \mathrm{mg}, 300 \mathrm{mg}$, and glimepiride, respectively). There was no reported serious case of diabetic ketoacidosis (DKA) related to canagliflozin use.

Similar to the results of other Phase 3 trials of SGLT2 inhibitors approved for use in the US (canagliflozin, dapagliflozin and empagliflozin), canagliflozin was associated with an increase in LDL-C levels in the CANTATA-SU trial [24-26]. The mean percent change in LDL-C increased from baseline to Week 26, and remained stable through Week 52 in all treatment groups; LS mean change (SE) from baseline at Week 52 
Table 5 Summary of selected AEs in the overall population

\begin{tabular}{|c|c|c|c|c|c|c|}
\hline & \multicolumn{3}{|c|}{ Baseline - 52 weeks } & \multicolumn{3}{|c|}{ Baseline - 104 weeks } \\
\hline & $\begin{array}{l}\text { CANA } 100 \mathrm{mg} \\
(\mathrm{N}=483)\end{array}$ & $\begin{array}{l}\text { CANA } 300 \mathrm{mg} \\
(N=485)\end{array}$ & $\begin{array}{l}\text { GLIM } \\
(N=482)\end{array}$ & $\begin{array}{l}\text { CANA } 100 \mathrm{mg} \\
(\mathrm{N}=483)\end{array}$ & $\begin{array}{l}\text { CANA } 300 \mathrm{mg} \\
(N=485)\end{array}$ & $\begin{array}{l}\text { GLIM } \\
(N=482)\end{array}$ \\
\hline & n (\%) & n (\%) & n (\%) & n (\%) & n (\%) & n (\%) \\
\hline Any AEs & $311(64.4)$ & $332(68.5)$ & $330(68.5)$ & $354(73.3)$ & $378(77.9)$ & $378(78.4)$ \\
\hline AEs leading to discontinuation & $25(5.2)$ & $32(6.6)$ & $28(5.8)$ & $30(6.2)$ & $46(9.5)$ & $35(7.3)$ \\
\hline Serious AEs & $24(5.0)$ & $26(5.4)$ & $39(8.1)$ & $47(9.7)$ & $47(9.7)$ & $69(14.3)$ \\
\hline Serious AEs leading to discontinuation & $6(1.2)$ & $5(1.0)$ & $10(2.1)$ & $8(1.7)$ & $8(1.6)$ & $13(2.7)$ \\
\hline \multicolumn{7}{|l|}{ Cardiovascular AEs } \\
\hline Cardiovascular death & $2(0.4)$ & 0 & $1(0.2)$ & $5(1.0)$ & 0 & $2(0.4)$ \\
\hline Nonfatal myocardial infarction & $2(0.4)$ & $1(0.2)$ & $1(0.2)$ & $4(0.8)$ & $3(0.6)$ & $4(0.8)$ \\
\hline Nonfatal stroke & $2(0.4)$ & $2(0.4)$ & 0 & $2(0.4)$ & $3(0.6)$ & $2(0.4)$ \\
\hline Hospitalized unstable angina & 0 & $1(0.2)$ & $1(0.2)$ & $1(0.2)$ & $1(0.2)$ & $1(0.2)$ \\
\hline MACE-plus & $5(1.0)$ & $4(0.8)$ & $3(0.6)$ & $10(2.1)$ & $7(1.4)$ & $9(1.9)$ \\
\hline Patients with any documented hypoglycemia ${ }^{a}$ & $27(5.6)$ & $24(4.9)$ & $165(34.2)$ & $33(6.8)$ & $40(8.2)$ & $197(40.9)$ \\
\hline Biochemically documented hypoglycemia & $26(5.4)$ & $21(4.3)$ & $164(34.0)$ & $32(6.6)$ & $39(8.0)$ & $197(40.9)$ \\
\hline Severe hypoglycemia & $2(0.4)$ & $3(0.6)$ & $15(3.1)$ & $3(0.6)$ & $1(0.2)$ & $16(3.3)$ \\
\hline Total number of episodes of documented hypoglycemia ${ }^{a}$ & 67 & 33 & 710 & 106 & 100 & 1189 \\
\hline \multicolumn{7}{|l|}{ Patients with documented hypoglycemia episodes, n (\%) } \\
\hline 1 episode & $11(2.3)$ & $17(3.5)$ & $45(9.3)$ & $15(3.1)$ & $24(4.9)$ & $44(9.1)$ \\
\hline 2 episodes & $7(1.4)$ & $5(1.0)$ & $32(6.6)$ & $7(1.4)$ & $8(1.6)$ & $34(7.1)$ \\
\hline$\geq 3$ episodes & $9(1.9)$ & $2(0.4)$ & $88(18.3)$ & $11(2.3)$ & $8(1.6)$ & $119(24.7)$ \\
\hline \multicolumn{7}{|l|}{ Genital mycotic infections } \\
\hline Male & $17(6.7)$ & $20(8.3)$ & $3(1.1)$ & $24(9.5)$ & $22(9.1)$ & $5(1.9)$ \\
\hline Female & $26(11.3)$ & $34(13.9)$ & $5(2.3)$ & $32(13.9)$ & $38(15.6)$ & $6(2.7)$ \\
\hline Urinary tract infections & $31(6.4)$ & $31(6.4)$ & $22(4.6)$ & $51(10.6)$ & $42(8.7)$ & $33(6.8)$ \\
\hline Osmotic diuresis-related AEs & $27(5.6)$ & $30(6.2)$ & $8(1.7)$ & $28(5.8)$ & $32(6.6)$ & $10(2.1)$ \\
\hline Pollakiuria & $12(2.5)$ & $12(2.5)$ & $1(0.2)$ & $13(2.7)$ & $12(2.5)$ & $2(0.4)$ \\
\hline Polyuria & $4(0.8)$ & $4(0.8)$ & $2(0.4)$ & $4(0.8)$ & $5(1.0)$ & $3(0.6)$ \\
\hline Volume depletion AEs & $8(1.7)$ & $9(1.9)$ & $8(1.7)$ & $8(1.7)$ & $12(2.5)$ & $11(2.3)$ \\
\hline
\end{tabular}

aEpisodes of hypoglycemia are prior to rescue medication; other AEs are regardless of rescue medication. AEs adverse events, CANA canagliflozin, GLIM glimepiride, MACE-plus major adverse cardiovascular events and events of hospitalized unstable angina

was 9.6 (1.9) for canagliflozin $100 \mathrm{mg}, 14.1$ (1.9) for canagliflozin $300 \mathrm{mg}$, and 5.0 (1.9) for glimepiride. There was no increase in the risk of bone fractures with canagliflozin use; the number of subjects with fracture AEs was 12 in canagliflozin $100 \mathrm{mg}$, and 13 in canagliflozin $300 \mathrm{mg}$ and glimepiride groups. Across treatment groups, $\leq 10 \%$ of subjects initiated or dose-adjusted for common antihypertensive agents. More subjects in the glimepiride group than in the canagliflozin groups initiated or had dose-adjusted common antihypertensive agents ( $\beta$-blockers, agents acting on the renin-angiotensin system, and calcium-channel blockers). The proportion of patients using other antihypertensive agents in the mITT population was higher at 104 weeks than at baseline in the glimepiride group (2.5 \% vs. $1.5 \%$ ) but remained similar in the canagliflozin $100 \mathrm{mg}$ group ( $2.5 \%$ vs. $2.1 \%)$ and canagliflozin $300 \mathrm{mg}$ group ( $3.1 \%$ vs. $2.7 \%$ ).

\section{Discussion}

Diabetes-related QMs are becoming increasingly important as indicators of quality of diabetes care. Our study showed a better attainment of diabetes-related measures with canagliflozin compared with glimepiride. Both doses of canagliflozin as well as glimepiride led to a decrease in $\mathrm{A} 1 \mathrm{C}$ values compared with baseline; however, canagliflozin $100 \mathrm{mg}$ resulted in similar or greater attainment of QMs related to glycemic control and BP, while canagliflozin $300 \mathrm{mg}$ resulted in superior attainment of QMs related to glycemic control and BP compared with glimepiride. 
The Eighth Joint National Committee recommends a BP target $<140 / 90 \mathrm{~mm} \mathrm{Hg}$ in diabetic patients, since reductions in BP in patients with diabetes who suffer from hypertension can improve cardiovascular health and mortality [27]. Our study showed that significantly more patients receiving both doses of canagliflozin achieved this target compared with glimepiride. Furthermore, this QM was attained even though higher proportions of patients in the glimepiride group were receiving antihypertensive agents.

Both canagliflozin doses resulted in more overweight or obese patients achieving weight loss. Weight gain in patients with T2DM has been shown to lead to patient frustration and can have a negative impact on medication adherence [28]. Conversely, weight loss in patients with T2DM has been associated with improved medication adherence, leading to the suggestion that diabetes medications that promote weight loss may be beneficial in this regard [29]. Other studies in obese patients with T2DM have demonstrated positive effects on psychological wellbeing and health-related quality of life as a result of achieving weight loss [30]. This post-hoc analysis showed that patients treated with canagliflozin $100 \mathrm{mg}$ or $300 \mathrm{mg}$ had larger decreases in body weight at 52 weeks compared with glimepiride, which were also maintained at 104 weeks. Additionally, among the patient subgroup with a BMI $\geq 25 \mathrm{~kg} / \mathrm{m}^{2}$, a greater proportion of patients in both canagliflozin groups, compared with the glimepiride group, were found to have lost $\geq 10 \mathrm{lb}(4.5 \mathrm{~kg})$ of body weight at 52 and 104 weeks. These results may indicate a beneficial effect of canagliflozin compared with maximally tolerated glimepiride in the achievement of diabetes QMs related to body weight. Although prevention of hypoglycemia is not a QM, there was a marked reduction in numbers of episodes when comparing both doses of canagliflozin with glimepiride, which might have further contributed to the weight benefits.

Similarly to the study presented here, a previous posthoc analysis compared the two doses of canagliflozin (100 $\mathrm{mg}$ and $300 \mathrm{mg}$ ) with the dipeptidyl peptidase-4 (DPP-4) inhibitor sitagliptin (100 $\mathrm{mg}$ ) in the attainment of diabetes-related QMs of glycemic control, BP, and body weight. Compared with sitagliptin, canagliflozin $100 \mathrm{mg}$ was associated with comparable or superior attainment of QMs, and canagliflozin $300 \mathrm{mg}$ was associated with superior attainment of all QMs [20], which shows a consistent benefit of canagliflozin over different AHAs.

Safety results of the CANTATA-SU trial indicate that canagliflozin is well-tolerated, with GMI and UTIs as the most common drug-related AEs. There have been reports of ketoacidosis in patients with type 1 diabetes and T2DM treated with SGLT2 inhibitors [31-33]; however, no serious incident of DKA related to canagliflozin was reported in this study. Erondu et al. recently analyzed all serious AEs of DKA and related events in 17,596 patients from randomized clinical trials of canagliflozin. Their findings support that the incidence of DKA and related events is rare with canagliflozin use $(0.07 \%)$ [34]. Similarly, the frequency of reported events of DKA was found to be low $(<0.1 \%)$ in randomized controlled trials involving SGLT2 inhibitors dapagliflozin (preliminary) and empagliflozin [35, 36].

Previous studies have shown that the use of SGLT2 inhibitors is associated with changes in lipid profiles [24, 26, 37] Pooled analyses of placebo-controlled Phase 3 trials of canagliflozin, dapagliflozin, and empagliflozin reported small increases in LDL-C and high-density lipoprotein-cholesterol, and small decreases in triglyceride levels from baseline [24-26]. Similarly in the CANTATA-SU trial, there was a small increase from baseline in the mean percent change in LDL-C levels with canagliflozin use. However, the clinical relevance of these changes in patients' lipid profiles is not clear and LDL-C treatment targets have been removed from the ACC/AHA Task Force on Practice Guidelines and HEDIS diabetes-related QMs [15]. Findings from the EMPA-REG OUTCOME study have shown that empagliflozin provides cardiovascular benefits in patients with T2DM at high risk for cardiovascular events [36]. Furthermore, a recent meta-analysis on the effects of SGLT2 inhibitors on cardiovascular events, death, and safety outcomes in adults with T2DM has suggested net protection of SGLT2 inhibitors against cardiovascular outcomes and death [38].

Patients with T2DM were shown to have a higher risk of fractures, which increases with advancing age and might be associated with the use of specific AHAs [39]. In a pool of 9 clinical trials, Watts et al. recently evaluated the occurrence of bone fractures with canagliflozin treatment and found that the incidence of fractures was similar in canagliflozin $(1.7 \%)$ and non-canagliflozin (1.5\%) groups in patients with no prior history/risk of cardiovascular disease [40]. Similarly in this study, no increase in the risk of fractures with canagliflozin use was observed.

The use of QMs is becoming increasingly important in the evaluation of the quality of care across healthcare delivery systems. For Accountable Care Organizations that participate in the Medicare Shared Savings Program, quality benchmarks have recently been established and the performance of participating organizations is judged against specific QMs before shared payments are made [41]. QMs also provide a foundation for initiatives such as Pay-for-Performance (P4P), which aim to reward physicians and non-physician clinicians for improvements in quality of care [42]. Since many patients with T2DM have hypertension, P4P programs not only reward the achievement of glycemic goals, but also goals associated with other parameters including BP [43]. 
A particular strength of this study is its use of data from a clinical trial that compared the efficacy and safety of canagliflozin with glimepiride, an active comparator drug. Other trials have compared a sulfonylurea with newer AHAs such as a DPP-4 inhibitor [44] or SGLT2 inhibitors dapagliflozin and empagliflozin [45, 46]. However, these studies limited the up-titration of the sulfonylurea to the initial 12 to 18 weeks of the study, thereby leading to a sub-optimal and less-clinically relevant comparison. The sub-optimal titration may drive the outcome to lower decreases in A1C for the sulfonylurea treatment group. In contrast, in the CANTATA-SU study, the sulfonylurea glimepiride was allowed to be up-titrated throughout the entire study period (104 weeks with a 52week primary endpoint time point) and did not have a fixed duration of titration. This resulted in a mean final dose achieved of $5.8 \mathrm{mg}$, allowing for a more relevant comparison with the study drug [22]. The A1C range specified in the patient eligibility criteria for inclusion in the clinical trial may limit the generalizability of the findings of this analysis to patients with more severe hyperglycemia (patients with $\mathrm{A} 1 \mathrm{C}>9.5 \%$ were not included in the trial [22]).

\section{Conclusions}

In this analysis of data from the randomized, doubleblind, Phase 3 CANTATA-SU trial, using the recently revised and currently accepted diabetes-related QMs, canagliflozin provided superior glycemic control compared with glimepiride in patients with T2DM who were poorly controlled on metformin monotherapy. Compared with glimepiride, canagliflozin resulted in improvement in QMs related to BP and weight loss, and was additionally associated with fewer incidences of hypoglycemic events. These observations on diabetesrelated QM attainment may be useful to those making decisions at the population level.

\begin{abstract}
Abbreviations
A1C, glycated hemoglobin; AACE, American Association of Clinical Endocrinologists; ACE, American College of Endocrinology; ADA, American Diabetes Association; $\mathrm{AE}$, adverse event; $\mathrm{AHA}$, antihyperglycemic agent; ANCOVA, analysis of covariance; BMI, body mass index; BP, blood pressure; BW, body weight; CANA, canagliflozin; CANTATA-SU, CANagliflozin Treatment And Trial Analysis Sulfonyl Urea; DBP, diastolic blood pressure; DPP-4, dipeptidyl peptidase-4; EASD, European Association for the Study of Diabetes; eGFR, estimated glomerular filtration rate; GLIM, glimepiride; GMI, genital mycotic infection; HEDIS, Healthcare Effectiveness Data and Information Set; LDL-C, low-density lipoprotein-C; LOCF, last observation carried forward; LS, least squares; mITT, modified intent-to-treat; P4P, pay-for-performance; $\mathrm{QM}$, quality measure; SBP, systolic blood pressure; SD, standard deviation; SE, standard error; SGLT2, sodium-glucose co-transporter 2; T2DM, type 2 diabetes mellitus; US, United States; UTI, urinary tract infection
\end{abstract}

\section{Acknowledgements}

Medical writing and editorial support was provided by Mihai Surducan, PhD and Bilge Yoruk, PhD of Excerpta Medica, and was funded by Janssen Scientific Affairs, LLC. Statistical programming and validation work were performed by Sue Wang and Weiping Li of Janssen Research \& Development,
LLC. Canagliflozin has been developed by Janssen Research \& Development, LLC, in collaboration with Mitsubishi Tanabe Pharma Corporation.

Funding

This analysis was sponsored by Janssen Scientific Affairs, LLC.

\section{Availability of data and materials}

The data that support the findings of this study are available from Janssen Scientific Affairs, LLC but restrictions apply to the availability of these data, which were used under license for the current study, and so are not publicly available. Data are however available from the authors upon reasonable request and with permission of Janssen Scientific Affairs, LLC.

\section{Authors' contributions}

CAP, RAB, UV, and GM contributed to the concept and design of the study, and the acquisition of the data. All authors (CAP, RAB, UV, GM, and LB) contributed to the analysis and interpretation of the data, drafting of the manuscript, and critical revision of the manuscript for important intellectual content. UV performed the statistical analysis. GM provided study materials or patients. All authors approved the final manuscript.

\section{Competing interests}

CAP and RAB are employees of Janssen Scientific Affairs, LLC. UV and GM are employees of Janssen Research and Development LLC. RAB, UV and GM own stock or stock options in Johnson \& Johnson. LB has served as an investigator for Lilly, Novo Nordisk and Sanofi; served as a speaker for Novo Nordisk, Sanofi, Merck, Janssen and AstraZeneca, and served as a consultant for Novo Nordisk, Sanofi, Merck, Janssen, Quest Diagnostics, AstraZeneca and GlaxoSmithKline.

\section{Consent for publication}

Not applicable.

\section{Ethics approval and consent to participate}

CANTATA-SU trial was conducted in accordance with the ethical principles that have their origin in the Declaration of Helsinki and that are consistent with Good Clinical Practices and applicable regulatory requirements. Permission was granted internally by Janssen R\&D LLC to utilize the clinical trial data in the current study. Institutional review boards or independent ethics committees at participating institutions approved the study protocol and amendments. Prior to participation, all patients provided written informed consent.

\section{Author details \\ 'Janssen Scientific Affairs, LLC, 1000 Route 202 South, Raritan, NJ 08869, USA. ${ }^{2}$ Janssen Research and Development, LLC, 920 US Route 202 South, Raritan, NJ 08869, USA. ${ }^{3}$ Ochsner Diabetes Clinical Research Unit, Frank Riddick Diabetes Institute, Department of Endocrinology, Ochsner Medical Center, 1515 Jefferson Highway, New Orleans, LA 70121, USA.}

Received: 14 January 2016 Accepted: 29 July 2016

Published online: 05 August 2016

\section{References}

1. American Diabetes Association. Standards of medical care in diabetes-2015. Diabetes Care. 2015;38 Suppl 1:S1-85

2. Inzucchi SE, Bergenstal RM, Buse JB, Diamant M, Ferrannini E, Nauck M, et al. Management of hyperglycemia in type 2 diabetes: a patient-centered approach: update to a position statement of the American Diabetes Association (ADA) and the European Association for the Study of Diabetes (EASD). Diabetes Care. 2015;38:140-9.

3. Inzucchi SE, Bergenstal RM, Buse JB, Diamant M, Ferrannini E, Nauck M, et al Management of hyperglycaemia in type 2 diabetes, 2015: a patient-centred approach. Update to a position statement of the American Diabetes Association and the European Association for the Study of Diabetes. Diabetologia. 2015;58:429-42.

4. Inzucchi SE, Bergenstal RM, Buse JB, Diamant M, Ferrannini E, Nauck M, et al. Management of hyperglycemia in type 2 diabetes: a patient-centered approach: position statement of the American Diabetes Association (ADA) and the European Association for the Study of Diabetes (EASD). Diabetes Care. 2012;35:1364-79. 
5. Inzucchi SE, Bergenstal RM, Buse JB, Diamant M, Ferrannini E, Nauck M, et al. Management of hyperglycaemia in type 2 diabetes: a patient-centered approach. Position statement of the American Diabetes Association (ADA) and the European Association for the Study of Diabetes (EASD). Diabetologia. 2012;55:1577-96

6. Handelsman Y, Bloomgarden ZT, Grunberger G, Umpierrez G, Zimmerman RS, Bailey TS, et al. American Association of Clinical Endocrinologists and American College of Endocrinology - clinical practice guidelines for developing a diabetes mellitus comprehensive care plan - 2015. Endocr Pract. 2015;21 Suppl 1:1-87.

7. Garber AJ, Abrahamson MJ, Barzilay Jl, Blonde L, Bloomgarden ZT, Bush MA, et al. AACE/ACE comprehensive diabetes management algorithm 2015. Endocr Pract. 2015;21:438-47.

8. O'Connor PJ, Bodkin NL, Fradkin J, Glasgow RE, Greenfield S, Gregg E, et al. Diabetes performance measures: current status and future directions. Diabetes Care. 2011;34:1651-9.

9. Dall TM, Yang W, Halder P, Pang B, Massoudi M, Wintfeld N, et al. The economic burden of elevated blood glucose levels in 2012: diagnosed and undiagnosed diabetes, gestational diabetes mellitus, and prediabetes. Diabetes Care. 2014;37:3172-9.

10. National Committee for Quality Assurance (NCQA). The state of health care quality. 2012. http://www.ncqa.org/ReportCards/HealthPlans/ StateofHealthCareQuality.aspx. (Archived Reports). Accessed 28 July 2015.

11. National Quality Measures Clearinghouse. Diabetes mellitus: percent of patients with a body mass index (BMI) greater than 25 who have lost 10 pounds at any time in the last 12 months. Agency for Healthcare Research and Quality website. http://www.qualitymeasures.ahrq.gov/content. aspx?id=27634. Accessed 4 December 2015.

12. Cebul RD, Love TE, Jain AK, Hebert CJ. Electronic health records and quality of diabetes care. N Engl J Med. 2011;365:825-33.

13. Centers for Medicare \& Medicade Services. Accountable Care Organization 2015 Program Analysis Quality Performance Standards Narrative Measure Specifications. https://www.cms.gov/medicare/medicare-fee-for-servicepayment/sharedsavingsprogram/downloads/aco-narrativemeasures-specs. pdf. Accessed 8 September 2015.

14. National Committee for Quality Assurance (NCQA). HEDIS 2015. 2015. http://www.ncqa.org/Portals///HomePage/Compiled_PC_Materials.pdf. Accessed 28 July 2015.

15. National Committee for Quality Assurance (NCQA). Proposed Changes to Existing Measure for HEDIS 1 2015: Comprehensive Diabetes Care (CDC). 2015. http://www.ncqa.org/Portals/0/HomePage/CDC.pdf. Accessed 8 September 2015.

16. Berhan A, Barker A. Sodium glucose co-transport 2 inhibitors in the treatment of type 2 diabetes mellitus: a meta-analysis of randomized double-blind controlled trials. BMC Endocr Disord. 2013;13:58.

17. Vasilakou D, Karagiannis T, Athanasiadou E, Mainou M, Liakos A, Bekiari E, et al. Sodium-glucose cotransporter 2 inhibitors for type 2 diabetes: a systematic review and meta-analysis. Ann Intern Med. 2013;159:262-74.

18. Wilding JP. The role of the kidneys in glucose homeostasis in type 2 diabetes: clinical implications and therapeutic significance through sodium glucose co-transporter 2 inhibitors. Metabolism. 2014;63:1228-37.

19. Janssen Pharmaceuticals, Inc. Invokana (canagliflozin). Prescribing Information, revised 05/2016. https://www.invokanahcp.com/sites/www. invokanahcp.com/files/prescribing-information-invokana.pdf. Accessed 8 Sept 2015.

20. Bailey RA, Vijapurkar U, Meininger GE, Rupnow MF, Blonde L. Diabetes-related quality measure attainment: canagliflozin vs. sitagliptin based on a pooled analysis of 2 clinical trials. Am J Manag Care. 2014;20 Suppl 13:S296-305.

21. Cefalu WT, Leiter LA, Yoon KH, Arias P, Niskanen L, Xie J, et al. Efficacy and safety of canagliflozin vs. glimepiride in patients with type 2 diabetes inadequately controlled with metformin (CANTATA-SU): 52 week results from a randomised, double-blind, phase 3 non-inferiority trial. Lancet. 2013;382:941-50.

22. Leiter $L A$, Yoon $K H$, Arias $P$, Langslet $G$, Xie J, Balis DA, et al. Canagliflozin provides durable glycemic improvements and body weight reduction over 104 weeks vs. glimepiride in patients with type 2 diabetes on metformin: a randomized, double-blind, phase 3 study. Diabetes Care. 2015;38:355-64.

23. National Institutes of Health $(\mathrm{NIH})$. Clinical Guidelines on the Identification Evaluation, and Treatment of Overweight and Obesity in Adults: The Evidence Report. NIH Publication No. 98-4083. 1998. http://www.nhlbi.nih. gov/guidelines/obesity/ob_gdlns.pdf. Accessed 30 July 2015.
24. Usiskin K, Kline I, Fung A, Mayer C, Meininger G. Safety and tolerability of canagliflozin in patients with type 2 diabetes mellitus: pooled analysis of phase 3 study results. Postgrad Med. 2014;126:16-34.

25. Ptaszynska A, Johnsson KM, Parikh SJ, de Bruin TW, Apanovitch AM, List JF. Safety Profile of Dapagliflozin for Type 2 Diabetes: Pooled Analysis of Clinical Studies for Overall Safety and Rare Events. Drug Saf. 2014;37(10): 815-29. doi:10.1007/s40264-014-0213-4.

26. McGill JB. The SGLT2 Inhibitor Empagliflozin for the Treatment of Type 2 Diabetes Mellitus: a Bench to Bedside Review. Diabetes Ther. 2014;5:43-63.

27. James PA, Oparil S, Carter BL, Cushman WC, Dennison-Himmelfarb C, Handler J, et al. 2014 evidence-based guideline for the management of high blood pressure in adults: report from the panel members appointed to the Eighth Joint National Committee (JNC 8). JAMA. 2014;311:507-20.

28. Pi-Sunyer $F X$. The impact of weight gain on motivation, compliance, and metabolic control in patients with type 2 diabetes mellitus. Postgrad Med. 2009;121:94-107.

29. Grandy S, Fox KM, Hardy E, SHIELD Study Group. Association of Weight Loss and Medication Adherence Among Adults With Type 2 Diabetes Mellitus: SHIELD (Study to Help Improve Early evaluation and management of risk factors Leading to Diabetes). Curr Ther Res Clin Exp. 2013;75:77-82.

30. Snel M, Sleddering MA, Vd Peijl ID, Romijn JA, Pij H, Meinders AE, Jazet IM. Quality of life in type 2 diabetes mellitus after a very low calorie diet and exercise. Eur J Intern Med. 2012;23:143-9.

31. Peters AL, Buschur EO, Buse JB, et al. Euglycemic diabetic ketoacidosis: a potential complication of treatment with sodium-glucose cotransporter 2 inhibition. Diabetes Care. 2015. doi:10.2337/dc15-0843.

32. Hine J, Paterson H, Abrol E, et al. SGLT inhibition and euglycaemic diabetic ketoacidosis. Lancet Diabetes Endocrinol. 2015;3:503-4.

33. Hayami T, Kato Y, Kamiya H, et al. Case of ketoacidosis by a sodium-glucose cotransporter 2 inhibitor in a diabetic patient with a low-carbohydrate diet. J Diabetes Investig. 2015;6:587-90.

34. Erondu N, Desai M, Ways K, Meininger G. Diabetic ketoacidosis and related events in the canagliflozin type 2 diabetes clinical program. Diabetes Care. 2015;38:1680-6.

35. Rosenstock J, Ferrannini E. Euglycemic Diabetic Ketoacidosis: A Predictable, Detectable, and Preventable Safety Concern With SGLT2 Inhibitors. Diabetes Care. 2015;38:1638-42. doi:10.2337/dc15-1380.

36. Zinman B, Wanner C, Lachin JM, for the EMPA-REG OUTCOMES Investigators, et al. Empagliflozin, cardiovascular outcomes, and mortality in type 2 diabetes. N Engl J Med. 2015. doi:10.1056/NEJMoa1504720.

37. Sjöström CD, Johansson P, Ptaszynska A, List J, Johnsson E. Dapagliflozin lowers blood pressure in hypertensive and non-hypertensive patients with type 2 diabetes. Diab Vasc Dis Res. 2015;12:352-8.

38. Wu HYJ, Foote C, Blomster J, Toyama T, Perkovic V, Sundström J, Neal B. Effects of sodium-glucose cotransporter-2 inhibitors on cardiovascular events, death, and major safety outcomes in adults with type 2 diabetes: a systematic review and meta-analysis. Lancet Diabetes Endocrinol. 2016:4(5):411-9.

39. Dede AD, Tournis S, Dontas I, Trovas G. Type 2 diabetes mellitus and fracture risk. Metabolism. 2014;63(12):1480-1490.40

40. Watts NB, Bilezikian JP, Usiskin K, Edwards R, Desai M, Law G, Meininger G. Effects of Canagliflozin on Fracture Risk in Patients With Type 2 Diabetes Mellitus. J Clin Endocrinol Metab. 2016;101(1):157-66. doi:10.1210/jc.20153167. Epub 2015 Nov 18

41. Medicare Shared Savings Program Quality Measure Benchmarks for the 2015 Reporting Year. 2015. http://www.cms.gov/Medicare/Medicare-Fee-forService-Payment/sharedsavingsprogram/Downloads/MSSP-QM-Benchmarks2015.pdf. Acccessed 28 July 2015.

42. Robert Wood Johnson Foundation, Health Affairs, Health Policy Brief. Payfor-performance: new payment systems reward doctors and hospitals for improving the quality of care, but studies to date show mixed results. 2012. http://healthaffairs.org/healthpolicybriefs/brief_pdfs/healthpolicybrief_78.pdf. Accessed 28 July 2015.

43. Integrated Healthcare Association Pay for Performance Measure Set Strategy: 2012-2015. 2015. http://www.iha.org/sites/default/files/resources/ my_2015_value_based_p4p_manual.pdf. Accessed 26 October 2015.

44. Nauck MA, Meininger G, Sheng D, Terranella L, Stein PP, Sitagliptin Study 024 Group. Efficacy and safety of the dipeptidyl peptidase- 4 inhibitor, sitagliptin, compared with the sulfonylurea, glipizide, in patients with type 2 diabetes inadequately controlled on metformin alone: a randomized, double-blind, non-inferiority trial. Diabetes Obes Metab. 2007;9:194-205. 
45. Nauck MA, Del Prato S, Meier JJ, Durán-García S, Rohwedder K, Elze M, Parikh SJ. Dapagliflozin vs. glipizide as add-on therapy in patients with type 2 diabetes who have inadequate glycemic control with metformin: a randomized, 52-week, double-blind, active-controlled noninferiority trial. Diabetes Care. 2011;34:2015-22.

46. Ridderstråle M, Andersen KR, Zeller C, Kim G, Woerle HJ, Broedl UC, EMPAREG H2H-SU trial investigator. Comparison of empagliflozin and glimepiride as add-on to metformin in patients with type 2 diabetes: a 104-week randomised, active-controlled, double-blind, phase 3 trial. Lancet Diabetes Endocrinol. 2014;2:691-700

Submit your next manuscript to BioMed Central and we will help you at every step:

- We accept pre-submission inquiries

- Our selector tool helps you to find the most relevant journal

- We provide round the clock customer support

- Convenient online submission

- Thorough peer review

- Inclusion in PubMed and all major indexing services

- Maximum visibility for your research

Submit your manuscript at www.biomedcentral.com/submit
Biomed Central 